\title{
Robotic Surgery for Large Renal Stones: Prospective Three Years Single-Institution Experience
}

\author{
Ahmed J. Al Sayyad, MD, FRCSC \\ Department of Urology, Faculty of Medicine, \\ King Abdulaziz University Jeddah, Saudi Arabia
}

\section{Correspondence}

Dr. Ahmed J. Al Sayyad

P.O. Box 1817, Jeddah 21441, Saudi Arabia

e.M: aalsayad@kau.edu.sa

\section{Submission: 15 Mar. 2015}

Accepted: $\quad 24$ Jun 2015

\section{Citation}

Al Sayyad AJ. Robotic surgery for large renal stones: prospective three years singleinstitution experience. JKAU Med Sci 2015; 22 (2): 31-37. DOI: 10.4197/Med. 22.2.5

\begin{abstract}
This prospective study evaluates the role of robotic surgery in the management of large renal stones. Robotic renal stone surgery is safe and effective, and may be considered among the treatment options for large renal calculi in adults, especially for patients with concomitant ureteropelvic junction obstruction. The benefits brought by robotic systems include improved 3-D visualization, greater dexterity, precision, and increased range of motion. Thus, robotic pyelolithotomy has been recommended for the treatment of renal calculi with concurrent upper tract abnormalities. The efficacy and safety of robotic pyelolithotomy as a treatment of large renal pelvic stones and partial staghorn stones is evident in our study, with a substantially high stone clearance rate. We were able to complete the robotic procedures safely and successfully in all but one of our 38 patients, who was converted to open surgery due to bleeding and severe adhesions. Overall, we found this procedure feasible, safe, efficacious, and high yielding in the management of large renal stones, especially when the procedure is accompanied by renal pelvis reconstructive surgery.
\end{abstract}

\section{Keywords}

Robotic surgery; Partial staghorn stones; Pyelolithotomy;

Pyeloplasty

\section{Introduction}

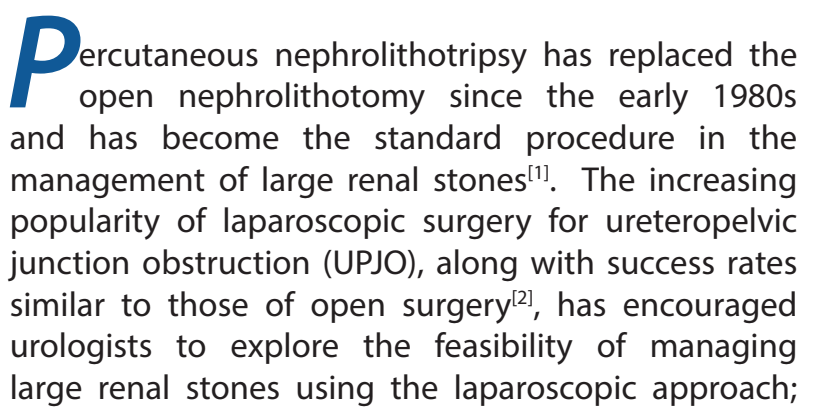

especially the renal stones with concomitant UPJO. Robotic surgery for upper urinary tract pathology has proved to be effective and advantageous to laparoscopic surgery ${ }^{[3,4]}$. Particularly, it demonstrated an outstanding success in renal surgeries, including radical and partial nephrectomies and pyeloplasty for UPJO $^{[5-8]}$. With the emergence of robotic pyeloplasty and its subsequently proved efficacy, pyelolithotomy has become an integrated part of this procedure when needed ${ }^{[8]}$. We report our three-year experience with using robotic surgery in our institution to manage 
large renal pelvic calculi and partial staghorn stones, with or without concomitant UPJO.

\section{Materials and Methods}

\section{Setting}

This prospective study was conducted at King Abdulaziz University Hospital between January 2010 and December 2012. The ethical committee approved the study and each patient provided an informed consent.

\section{Patients Selection}

We included adult patients who underwent robotic pyelonephrolithotomy. Inclusion criteria were adults ( $\geq 18$ years-old) with large renal pelvic stones ( $>30$ $\mathrm{mm}$ ) with or without multiple small caliceal stones; or partial staghorn stones with 1-2 caliceal stones. Both radiopaque and radiolucent calculi not responding to medical treatment were included. Stones with concomitant UPJO were included as well. All patients were symptomatic at presentation (flank pain and/or hematuria). Exclusion criteria were patients under the age of 18 years-old and patients with previous renal surgeries.
All patients performed the routine preoperative laboratory tests including urine culture, non-enhanced computerized tomography scan of abdomen and pelvis (Figs. 1 and 2) and diethylene triamine pentaacetic acid (DTPA) renal scan for the patients with concomitant UPJO. Prophylactic third generation cephalosporin were given to all patients prior to the surgery.

\section{Technique}

All procedures were performed through the transperitoneal approach using 3-arm da Vinci robotic surgical system (Intuitive Surgical). After induction of general anesthesia, while the patient was in lithotomy position, cystoscopy with insertion of double-J stent was performed. If that seemed difficult a ureteric catheter was inserted just distal the stone to facilitate stent insertion after stone removal.

The patient was then placed in a flank position with no flexion of the operating table. Pneumoperitoneum was developed and four ports were placed as shown in Figure 3. The $12 \mathrm{~mm}$ camera port was placed 2-3 fingerbreadths lateral and superior to the umbilicus. Two robotic arms $8 \mathrm{~mm}$ ports were inserted a handbreadth superior and inferior to the camera port. A fourth $10 \mathrm{~mm}$ assistant port was inserted between the camera port and the lower robotic arm port.

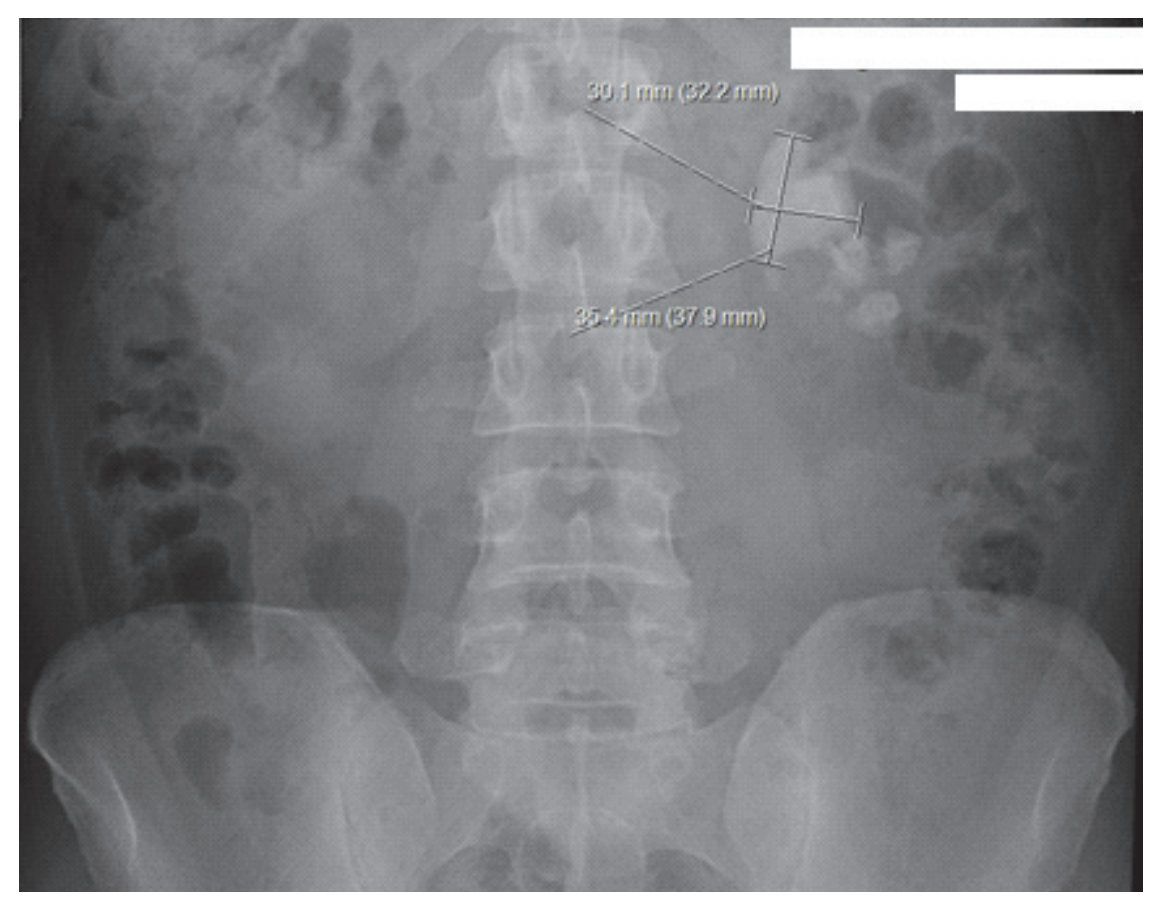

Figure 1. Pre-operative image of partial staghorn stone with multiple lower caliceal calculi. 

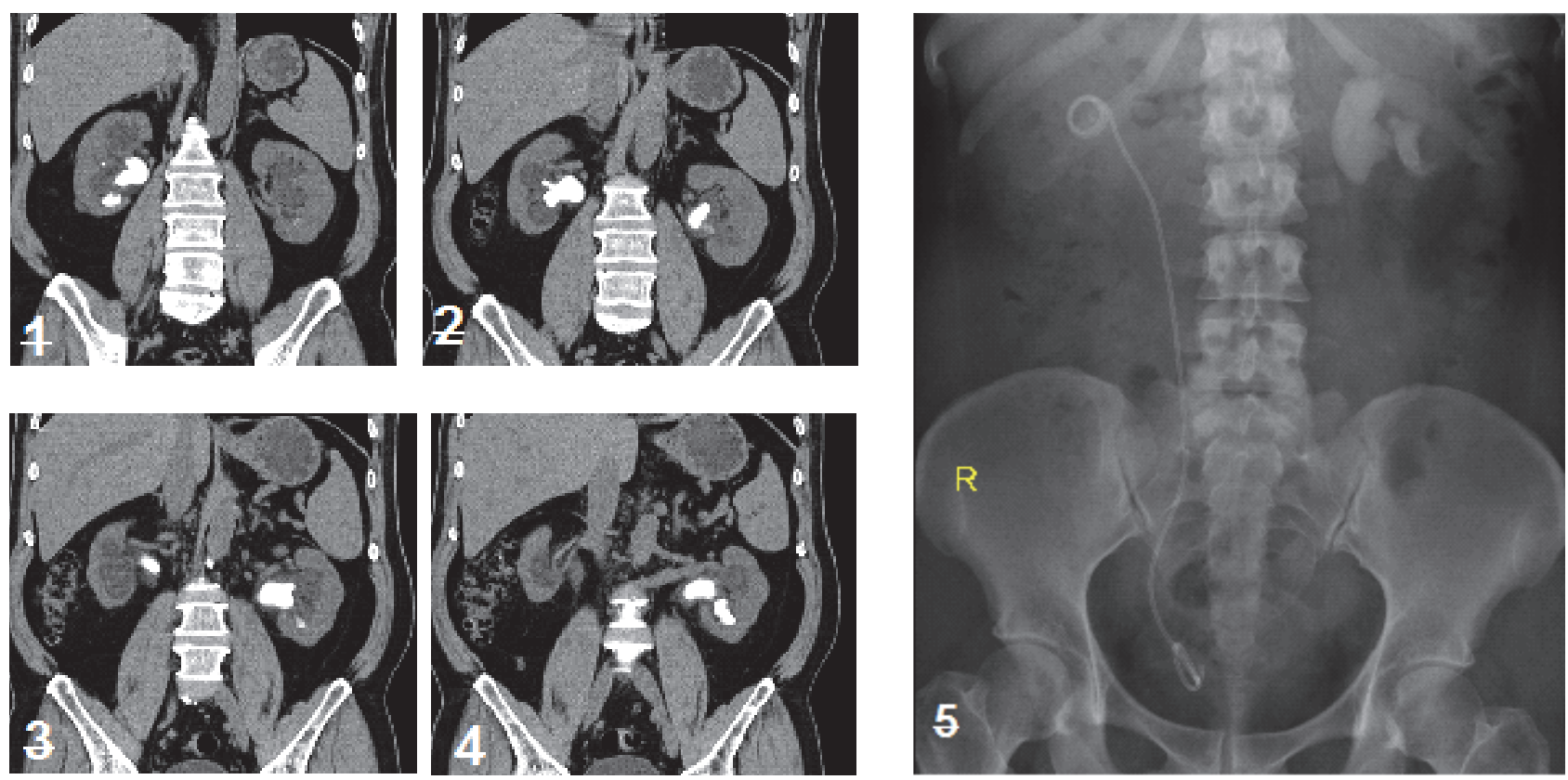

Figure 2. Frames 1-4: Pre-operative CT for bilateral large multiple renal calculi. Frame 5: Post-operative image after right robotic pyelolithotomy showing double-J stent and stone-free right kidney.

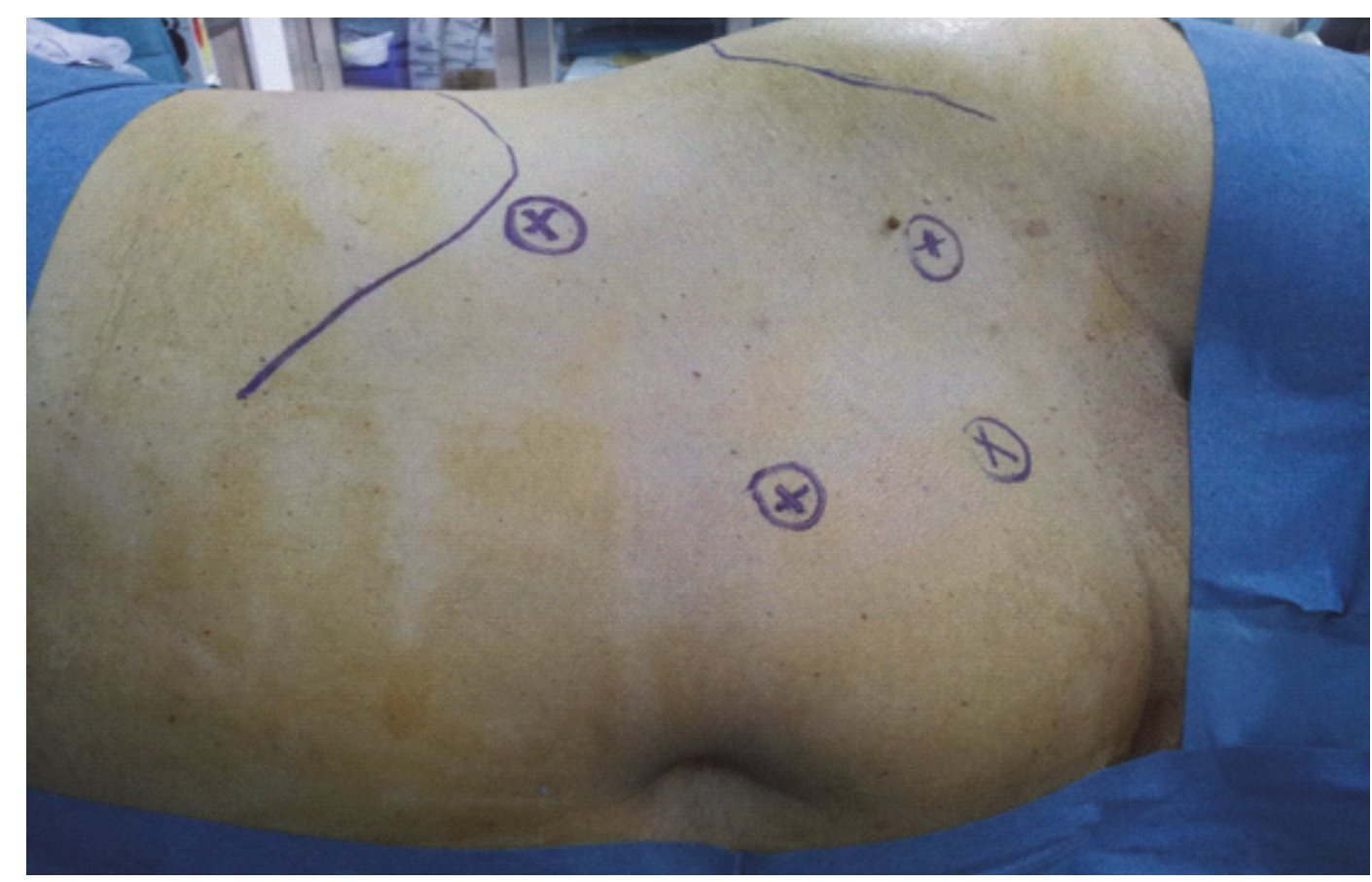

Figure 3. Positioning of the patient, and the sites of ports for robotic pyelolithotomy. 

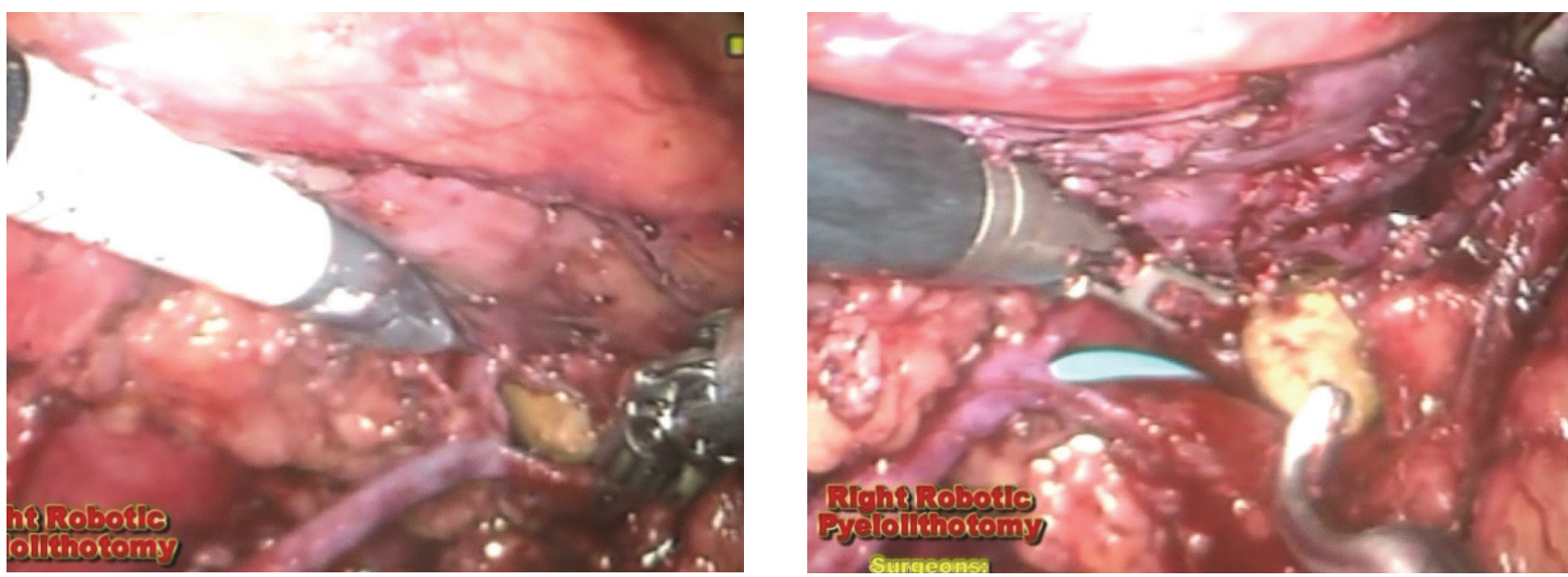

Figure 4. Intraoperative pictures demonstrating the opened pelvis with the stone inside the pelvis (Frame 1), and the double-J stent (Frame 2).

After medial reflection of the colon, the ureter was identified and traced up to the renal pelvis where complete dissection is a key factor. Often there is much adherent inflamed fat around the renal pelvis, which requires cleaning. Careful attention to the renal hilum vessels is important at this point since they become very close to the working field. Once the pelvis was dissected and prepared, a vertical incision was made over the stone with scissors, and then the stone was delivered with a stone forceps (Fig. 4). We often used a laparoscopic right angle forceps to release the inside adhesions of the stone. In case there were more stones that could not be reached, flexible cystoscopy was inserted through the renal pelvis incision and the stones were removed with a grasper or basket. The stones were removed through the $12 \mathrm{~mm}$ port, while large stones were placed in a specimen bag and removed at the end of the operation. After all stones were cleared, we ensured proper positioning of the DJ stent, then the renal pelvis was closed with running 4-0 Vicryl sutures (Ethicon Inc., Somerville, NJ USA). In patients with coexisting UPJO, robotic Anderson-Hynes dismembered pyeloplasty or Heineke-Mikulicz repair were utilized. A suction drain was left at the site of operation, and was brought through one of the ports.

\section{Results}

Patients' age varied between 24-53 years old, with a mean of 40.3 years. Thirty (78.9\%) patients were males, while eight patients were females. In 24 (63.2\%) patients, the stones were located on the right side, whereas 14 patients harbored stones in the left side
(Table 1). Thirty-two (84.2\%) patients had partial staghorn stone, and six patients had large solitary stone $(>30 \mathrm{~mm}$ ) with or without multiple small caliceal stones. The mean stone size was approximately 45 $\mathrm{mm}$ (32-59). Thirty-two (84.2\%) of patients had an extrarenal pelvis while the remaining six patients had an intrarenal pelvis. Sixteen $(42.1 \%)$ patients had concomitant UPJO and underwent concomitant repair. The mean operative time was 173 minutes (165-257) (timed from the placement of the Veress needle to skin closure). The mean robotic console time was 148 minutes (134-186). The estimated blood loss ranged between 100-500 cc, with a mean of $150 \mathrm{cc}$. The mean hospital stay was 3 days (2-5). The follow-up period varied between 4-18 months with a mean of 13 months. All procedures were successfully completed

Table 1. Patients' demographics and characteristics.

\begin{tabular}{|l|c|}
\hline \multicolumn{1}{|c|}{ Characteristics } \\
\hline Patients $(\mathrm{n})$ & 38 \\
\hline Mean age, years; mean (range) & $40.3(24-53)$ \\
\hline Male, $\mathrm{n}(\%)$ & $30(78.90 \%)$ \\
Female, $\mathrm{n}(\%)$ & $8(21.10 \%)$ \\
\hline Right side, $\mathrm{n}(\%)$ & $24(63.20 \%)$ \\
Left side, $\mathrm{n}(\%)$ & $14(36.80 \%)$ \\
\hline Extrarenal pelvis, $\mathrm{n}(\%)$ & $32(84.20 \%)$ \\
Intrarenal pelvis, $\mathrm{n}(\%)$ & $6(15.80 \%)$ \\
\hline Partial staghorn stone & $32(84.20 \%)$ \\
Large solitary stone & $6(15.8 \%)$ \\
\hline Stone size, mm; mean (range) & $45(32-59)$ \\
\hline Concomitant UPJ0, $\mathrm{n}(\%)^{\dagger}$ & $16(42.10 \%)$ \\
\hline
\end{tabular}

Large solitary stone $>30 \mathrm{~mm}$, with or without multiple small caliceal stones. UPJO = Ureteropelvic junction obstruction 
Table 2. Perioperative outcomes.

\begin{tabular}{|l|c|}
\hline \multicolumn{1}{|c|}{ Variable } & \\
\hline Operative time, min & $173(165-257)$ \\
\hline Console time, min & $148(134-186)$ \\
\hline Estimated blood loss, $\mathrm{mL}$ & $150(100-500)$ \\
\hline Hospital stay, day & $3(2-5)$ \\
\hline Follow-up, months & $13(4-18)$ \\
\hline Conversion to open & 1 \\
\hline Residual stones & 1 \\
\hline Post-operative complications, ileus & 1 \\
\hline
\end{tabular}

via robotic surgery, except one patient who was converted to open surgery due to bleeding and severe adhesions. There was no evidence of residual stones in the postoperative imaging of $37(97.4 \%)$ patients. One patient demonstrated small residual caliceal stones, which were treated successfully by extracorporeal shock wave lithotripsy. One patient developed postoperative ileus, which subsided uneventfully after two days (Table 2). No other significant perioperative complications were observed, and none of the patients have required a blood transfusion.

\section{Discussion}

Renal stone management has evolved dramatically, starting from open technique passing through extracorporeal shock wave lithotripsy, uretroscopy to the percutaneous nephrolithotomy which has become the treatment of choice for large staghorn calculi $^{[1]}$. Nevertheless, the evolution continues, especially with the introduction of laparoscopy in the management of renal stones, described in 1983 by Wickham ${ }^{[9]}$, and many studies have subsequently described laparoscopic management of urinary stones $^{[10-14]}$. Whereas Schuessler et al. ${ }^{[15]}$ introduced the role of laparoscopic pyeloplasty in 1993, a decade later Gettman and colleagues ${ }^{[7]}$ reported on AndersonHynes dismembered pyeloplasty performed with the da Vinci robotic system. Mufarrij and coworkers ${ }^{[8]}$ presented a series of 140 robotic pyeloplasty; of them 13 patients underwent concomitant stone extraction. They concluded the safety, durability and efficacy of the procedure for the repair of primary and secondary UPJO and for removal of stones. Many other studies have proven the success of robot assisted laparoscopic pyelolithotomy as well. Lee et al. ${ }^{[16]}$ presented their data in robot assisted laparoscopic pyelolithotomy with five patients and they concluded that the procedure was safe and efficacious. Badani et al. ${ }^{[17]}$ also reported the feasibility and safety of robotic extended pyelolithotomy with an average stone size of $4.2 \mathrm{~cm}$. Further, Atug et al. ${ }^{[18]}$ reported the concurrent stone extraction and UPJO repair using robotic laparoscopic surgery to be a safe and successful procedure. The benefits brought by robotic systems include improved 3-D visualization, greater dexterity, precision, and increased range of motion. Thus, robotic pyelolithotomy has been recommended for treatment of renal calculi with concurrent upper tract abnormalities; e.g., UPJO, pelvic kidney, and caliceal diverticulum ${ }^{[8,16-18]}$.

In the current study, all procedures were performed transperitoneally, using the 3 -arm da Vinci robotic surgical system. We utilized robotic assistance in all dissections, except the dissections of the stones, which were done by robotic forceps and/or laparoscopic right angle forceps. The majority of our patients (84.2\%) had an extra renal pelvis. The dissections and stone extraction were much easier in the extra renal pelves compared to the intrarenal pelves, which necessitated more intra hilar exposure. We performed concomitant dismembered pyeloplasty in 16 patients, who had renal stones with coexisting UPJO.

The efficacy and safety of robotic pyelolithotomy as a treatment of large renal pelvic stones and partial staghorn stones was evident in our study, with a substantially high stone clearance rate (97.4\%). We were able to complete the robotic procedures safely and successfully in the majority of patients. We converted to open surgery in one patient only due to severe adhesions and bleeding. Furthermore, with a mean operative time of less than three hours (173 minutes), mean hospital stay of three days, minimal blood loss (mean of $150 \mathrm{cc}$ ) and no reported significant postoperative complications, we deduce the safety of this robotic transperitoneal approach. Overall, we found this procedure feasible, safe, efficacious, and high yielding in the management of large renal stones, especially when the procedure is accompanied by renal pelvis reconstructive surgery.

\section{Conclusion}

Robotic stone surgery is safe and effective; and may be considered as an option in the management of large renal stones, especially those with concurrent UPJO. Further studies are required to better clarify the indications of robotic renal stone surgery. 
Robotic Surgery for Large Renal Stones: Prospective Three Years Single-Institution Experience A.J. Al Sayyad

\section{Acknowledgments}

Professor Taha A. Abdel-Meguid, Department of Urology, Faculty of Medicine, King Abdulaziz University, Jeddah, Saudi Arabia, provided revision and criticism.

\section{Conflict of Interest}

The author has no conflict of interest.

\section{Disclosure}

The author did not received any type of commercial support either in forms of compensation or financial for this study. The author has no financial interest in any of the products or devices, or drugs mentioned in this article.

\section{Ethical Approval}

Obtained.

\section{References}

[1] Preminger GM, Assimos DG, Lingeman JE, Nakada SY, Pearle MS, Wolf JS Jr; AUA Nephrolithiasis Guideline Panel). Chapter 1: AUA guideline on management of staghorn calculi: diagnosis and treatment recommendations. J Urol 2005; 173(6): 1991-2000

[2] Bansal P, Gupta A, Mongha R, Narayan S, Das RK, Bera M, Chakraborty SC, Kundu AK. Laparoscopic versus open pyeloplasty: comparison of two surgical approaches-a single centre experience of three years. Indian J Surg 2011; 73(4): 264-267

[3] Braga LHP, Pace K, DeMaria J, Lorenzo AJ. Systematic review and meta-analysis of robotic-assisted versus conventional laparoscopic pyeloplasty for patients with ureteropelvic junction obstruction: Effect on operative time, length of hospital stay, postoperative complications, and success rate. Eur Urol 2009; 56(5): 848-858.

[4] Sivaraman A, Leveillee RJ, Patel MB, Chauhan S, Bracho JE 2nd, Moore CR, Coelho RF, Palmer KJ, Schatloff O, Bird VG, Munver R, Patel VR. Robot-assisted laparoscopic dismembered pyeloplasty for ureteropelvic junction obstruction: A multi-institutional experience. Urology 2012; 79(2): 351-355.

[5] Palese MA, Munver R, Phillips CK, Dinlenc C, Stifelman M, DelPizzo JJ. Robot-assisted laparoscopic dismembered pyeloplasty. JSLS 2005; 9(3): 252-257.

[6] Hu JC, Treat E, Filson CP, McLaren I, Xiong S, Stepanian S, Hafez KS, Weizer AZ, Porter J. Technique and outcomes of robot-assisted retroperitoneoscopic partial nephrectomy: a multicenter study. EurUrol 2014; 66(3): 542-549.

[7] Gettman MT, Neururer R, Bartsch G, Peschel R. AndersonHynes dismembered pyeloplasty performed with the da Vinci robotic system. Urology 2002; 60(3): 509-513.
[8] Mufarrij PW, Woods M, Shah OD, Palese MA, Berger AD, Thomas R, Stifelman MD. Robotic dismembered pyeloplasty: a 6-year, multi-institutional experience. J Urol 2008; 180(4): 1391-1396.

[9] Wickham JEA. The surgical treatment of urinary lithiasis In: Urinary Calculus Disease. Wickham JEA, ed. Edinburgh: Churchill Livingstone, 1979. 145-198.

[10] Keeley FX, Gialas I, Pillai M, Chrisofos M, Tolley DA. Laparoscopic ureterolithotomy: the Edinburgh experience. BJU Int 1999; 84(7): 765-769.

[11] Harewood LM, Webb DR, Pope AJ. Laparoscopic ureterolithotomy: the results of an initial series, and an evaluation of its role in the management of ureteric calculi. Br J Urol 1994; 74(2): 170-176.

[12] Türk I, Deger S, Roigas J, Fahlenkamp D, Schönberger B, Loening SA. Laparoscopic ureterolithotomy. Tech Urol 1998; 4(1): 29-34.

[13] Coptcoat MJ, Coker C, Mulvin DM. Laparoscopy in urology: a clinical review of 359 cases. In: Laparoscopic Urologic Surgery Retroperitoneal and Transperitoneal. Hemal AK, ed. Chapt.37. New Delhi: B.I. Churchill Livingstone, 2000. 309322.

[14] Micali S, Moore RG, Averch TD, Adams JB, Kavoussi LR. The role of laparoscopy in the treatment of renal and ureteral calculi. J Urol 1997; 157(2): 463-466.

[15] Schuessler WW, Grune MT, Tecuanhuey LV, Preminger GM Laparoscopic dismembered pyeloplasty. J Urol 1993; 150(6): 1795-1799.

[16] Lee RS, Passerotti CC, Cendron M, Estrada CR, Borer $J G$, Peters CA. Early results of robot assisted laparoscopic lithotomy in adolescents. J Urol 2007; 177(6): 2306-2309.

[17] Badani KK, Hemal AK, Fumo M, Kaul S, Shrivastava A, Rajendram AK, Yusoff NA, Sundram M, Woo S, Peabody JO, Mohamed SR, Menon M. Robotic extended pyelolithotomy for treatment of renal calculi: A feasibility study. World J Urol 2006; 24(2): 198-201.

[18] Atug F, Castle EP, Burgess SV, Thomas R. Concomitant management of renal calculi and pelvi-ureteric junction obstruction with robotic laparoscopic surgery. BJU Int 2005; 96(9): 1365-1368. 


\title{
جراحة الروبوت لعلاج حصوات الكلية الكبيزة: خبرة ثلاث سنوات
}

\author{
احمد جلال الصباد \\ قسم الدسالك البولية، كلية الطب، جامعة الدلك عبدالعزيز \\ جلة - المدلكة العربية السعودية العية هابة
}

المستخلص. هذه الدر اسة المستقلية تمت لتقييم دور الجراحة الروبوتية في علاج حصيات الكلوية الكبيرة. أثتت جراحة الكلى الروبوتية أنها آمنة وفعالة، ويمكن اعتبار ها من بين الخيارات المتاحة لعلاج الحصيات الكلوية الكبيرة في البالغين،

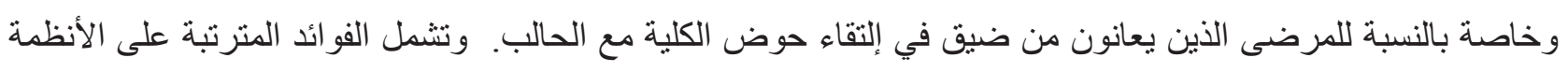

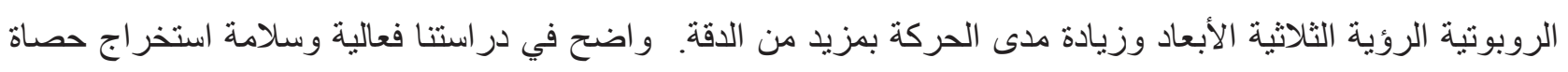

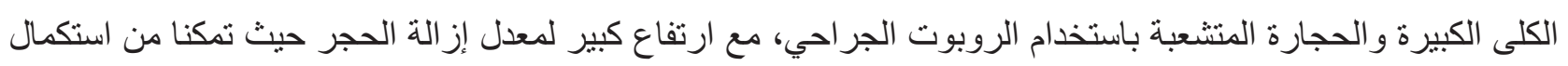

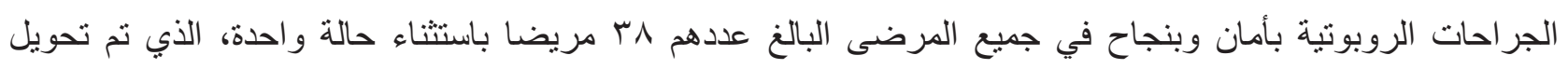

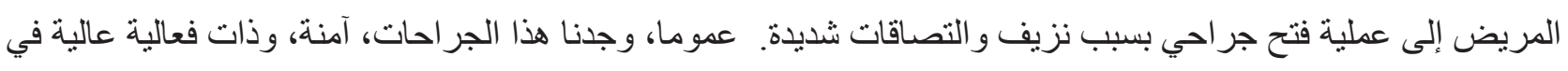
استخر اج الحصيات الكلوية الكبيرة، وخصوصا عندما يقترن ذلك باجر اء جراحة لاصلاح ضيق التقاء وهنئ حوض الكلية مع 